Supporting Information

\title{
The adduct of aquacobalamin with hydrogen peroxide
}

Maria Lehene, ${ }^{1}$ Diana Pleșa, ${ }^{1}$ Stefania Ionescu-Zinca, ${ }^{1}$ Stefania D. Iancu, ${ }^{2}$ Nicolae Leopold, ${ }^{2}$ Sergei V. Makarov, ${ }^{3}$ Adrian M.V. Brânzanic, ${ }^{1}$ Radu Silaghi-Dumitrescu ${ }^{1 *}$

${ }^{1}$ Department of Chemistry, Babeș-Bolyai University, Str. Arany Janos Nr. 11, RO-400028 ClujNapoca, Romania

${ }^{2}$ Faculty of Physics, Babeș-Bolyai University, Str. Kogalniceanu 1, RO-400084 Cluj-Napoca, Romania

${ }^{3}$ Ivanovo State University of Chemistry and Technology, Sheremetevskiy Str. 7, 153000 Ivanovo, Russia

*Correspondence to: rsilaghi@chem.ubbcluj.ro

\section{Materials and Methods}

Hydroxocobalamin hydrochloride ( $\mathrm{HOCbl}, \geq 98 \%$ ) was obtained from Sigma-Aldrich (Munich, Germany) and used as received and hydrogen peroxide $30 \%$ was obtained from ChemPUR. The buffer used was the Britton-Robinson buffer, it consists of a mixture of $\mathrm{H}_{2} \mathrm{BO}_{3}$, $\mathrm{H}_{3} \mathrm{PO}_{4}$ and $\mathrm{CH}_{3} \mathrm{COOH}$, that has been titrated to the wanted $\mathrm{pH}$ with $\mathrm{NaOH}$.

UV-vis spectra were performed on a Cary 50 UV-vis spectrophotometer (Varian, Inc., Foster City, CA, USA). Stopped-flow spectra were collected on a Biologic SFM-300 system equipped with three syringes and sequential mixing, with a high-speed diode array detector. The stopped-flow data were processed with the SPECFIT32 software package (BioLogic system, Claix, France) using a single process for fitting. Time course graphs are listed in Figures at 435 $\mathrm{nm}$, specific for the peroxide adduct.

For DFT calculations, the Gaussian09 software package ${ }^{1}$ was employed. The Cbl models were truncated, with the lateral substituents on the corrin as well as the methyl groups on the benzimidazole replaced by hydrogen. Gas-phase geometries and frequency analyses were computed with the aid of the B3LYP ${ }^{2,3}$ functional at the def2-SV $(\mathrm{P})^{4}$ double-zeta basis set level. Long-range interactions were accounted by the use of Grimme's D3 dispersion correction. ${ }^{4}$ The chosen computational framework follows a methodology previously verified in detail to perform 
optimally (over a range of other functional/basis sets) for related bioinorganic centers. ${ }^{5}$ Population analyses, $\mathrm{NMR}^{6}$ and TD-DFT derived ${ }^{6} \mathrm{UV}-\mathrm{V}$ is spectra were computed in the C-PCM solvent continuum adapted for aqueous environment. ${ }^{7}$ For the latter property the B3PW91 ${ }^{2,8}$ functional outperformed B3LYP and was subsequently employed. Data for the lowest-spin states are shown for each model, unless otherwise specified. Qualitatively similar data were obtained in Spartan software package using B3LYP/6-31+G* , and the TD-DFT algorithm. ${ }^{9}$ DFT-derived spectral data were obtained using Chemcraft; ${ }^{10}$ for the Raman simulations, $298 \mathrm{~K}$ and an excitation wavelength of $22000 \mathrm{~cm}^{-1}$ were assumed.

The NMR spectra were recorded at $22^{\circ} \mathrm{C}$ unless otherwise stated, after diluting the sample (at concentrations indicated in text and Figure legends) with $\mathrm{D}_{2} \mathrm{O}$ (1:1 volume ratio), on a 400 $\mathrm{MHz}$ Bruker instrument.

Raman spectra were measured at $22^{\circ} \mathrm{C}$ on a Renishaw inVia Raman spectrometer coupled with a Leica microscope. $10 \mu \mathrm{l}$ of the sample was dropped on a microscope slide covered with aluminum foil. The $532 \mathrm{~nm}$ laser line with a power of $50 \mathrm{~mW}$ was focused on the sample by using a $5 \mathrm{X}$ objective. Each spectrum is represented as an average of 4 accumulations, 4 seconds each.

Liquid chromatography coupled with UV-Vis detection (LC-UV-vis) was performed using an HPLC Agilent 1260 Infinity Series instrument (Agilent Technologies Inc., 2012), using a Zorbax Eclipse XDB-C8 column, with a methanol-water mobile phase (7:3) at $0.5 \mathrm{~mL} / \mathrm{min}$. The samples were $0.74 \mathrm{mM}$ aquaCbl with or without $50 \mathrm{mM}$ hydrogen peroxide, in $50 \mathrm{mM}$ phosphate, $\mathrm{pH} 7$. 

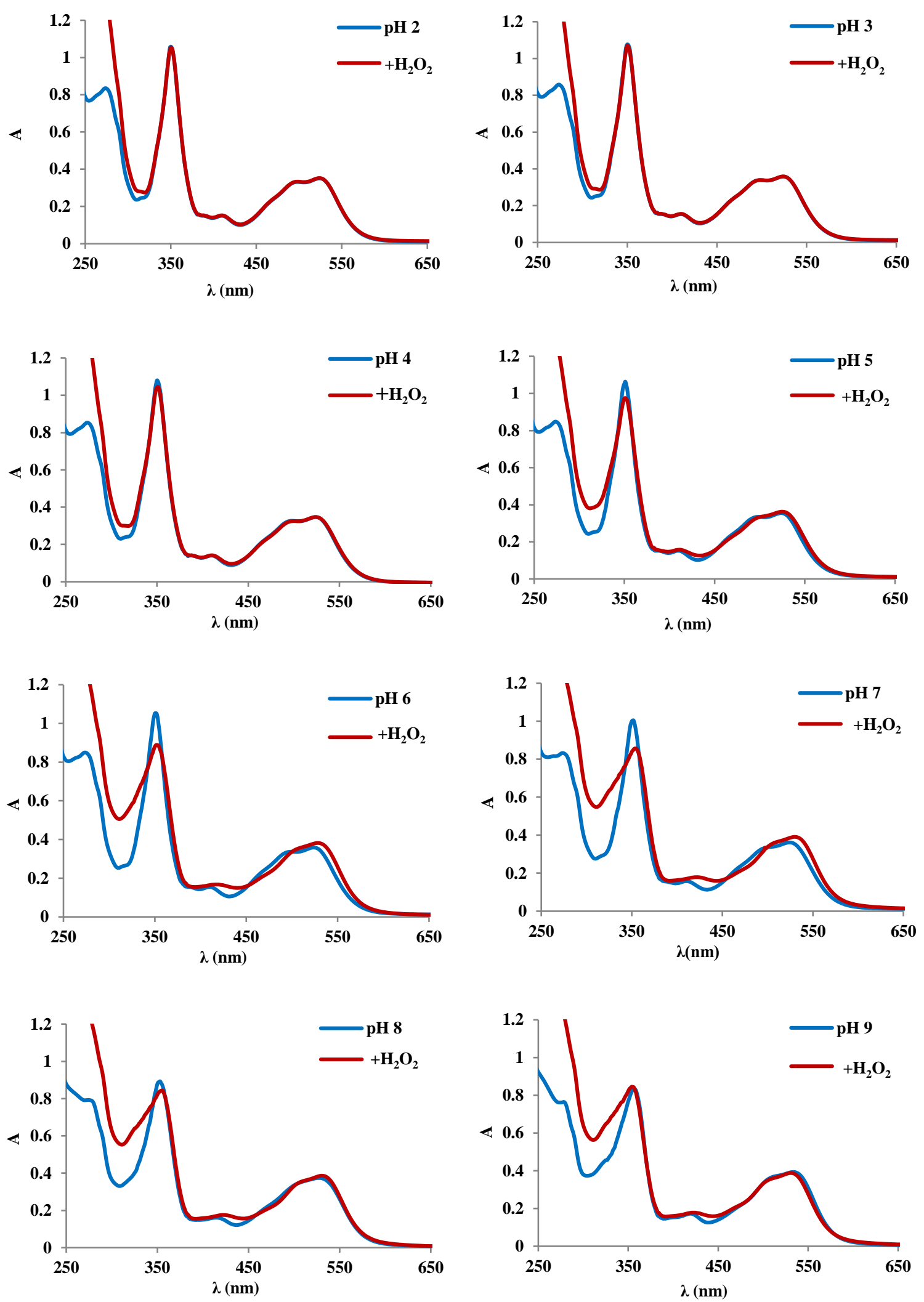

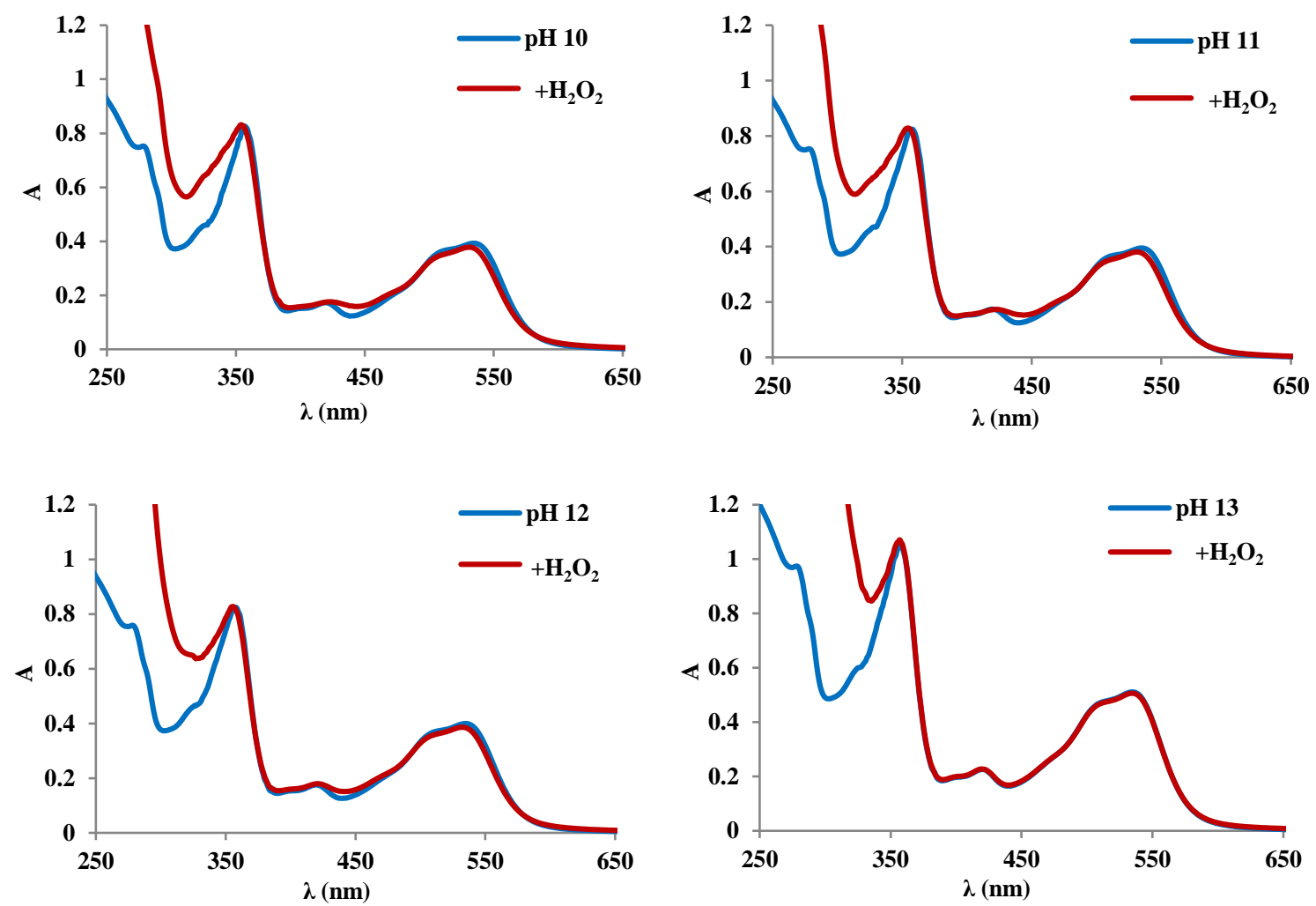

Figure S1. UV-vis spectra of $\mathrm{Co}(\mathrm{III})$ cobalamin treated with hydrogen peroxide, at $\mathrm{pH}$ 2-13. Conditions: $0.5 \mathrm{mM} \mathrm{Cbl,} 50 \mathrm{mM} \mathrm{H}_{2} \mathrm{O}_{2}, 22^{\circ} \mathrm{C}$.

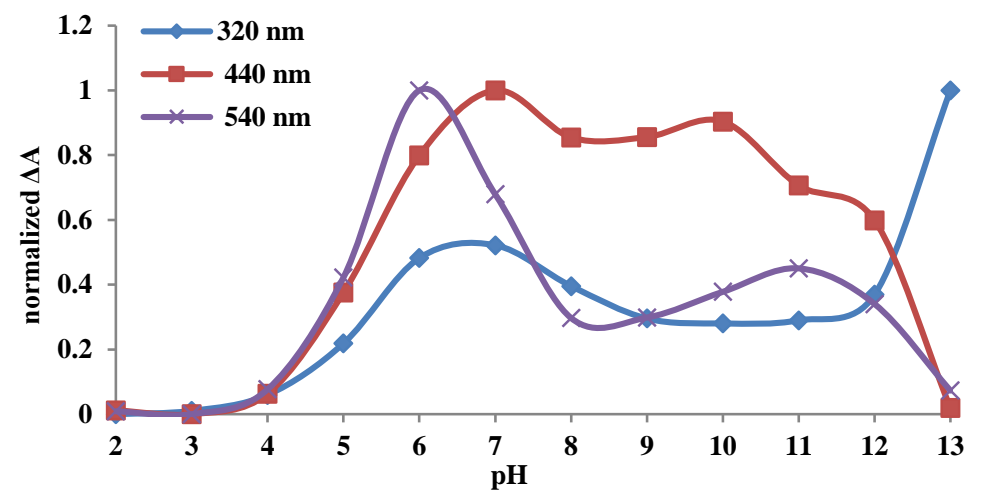

Figure S2. Variation of absorbance at relevant wavelengths upon binding peroxide to Cbl(III), based on spectra shown in Figures 1 and S1. Values are normalized at each wavelength so as to range for 0 to 1 . 


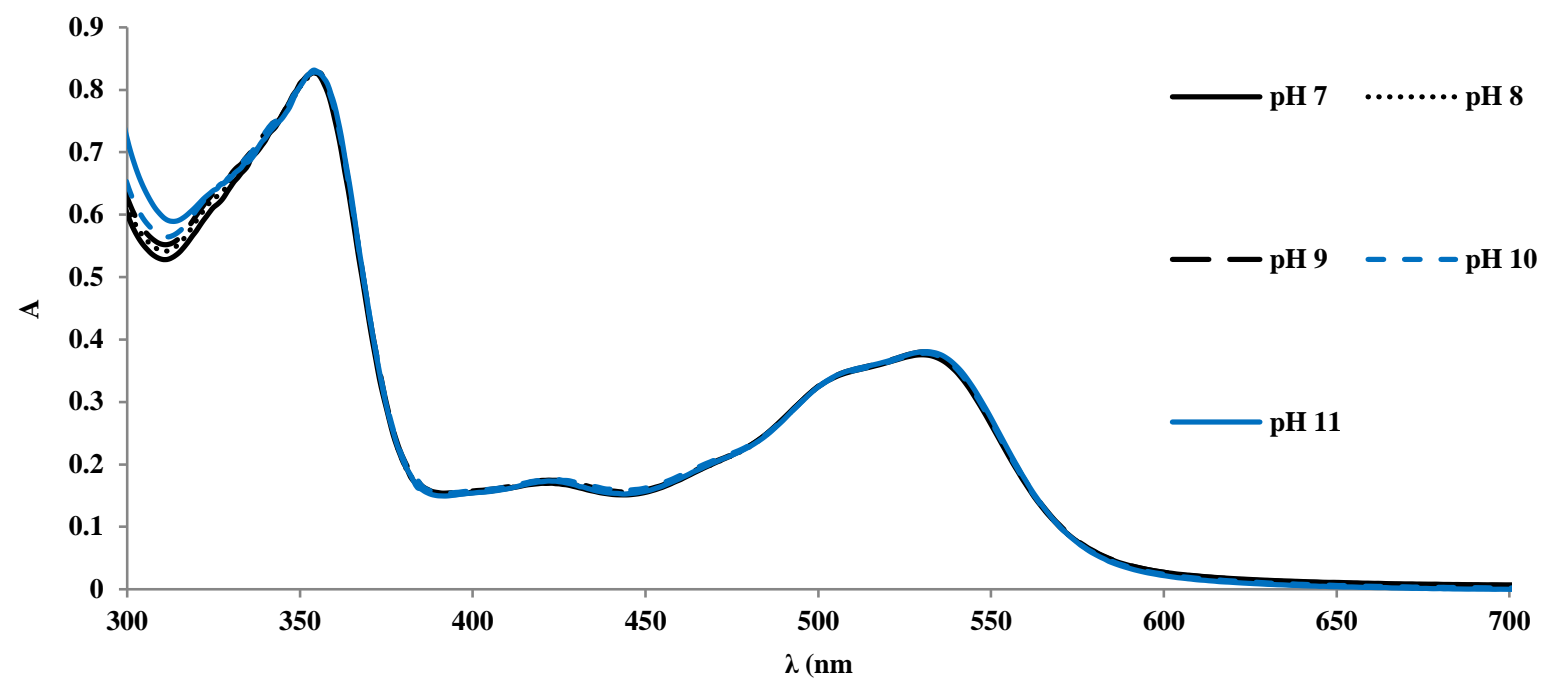

Figure S3. The peroxo-Cbl spectrum at pH 7-11 (data from Figure 1).

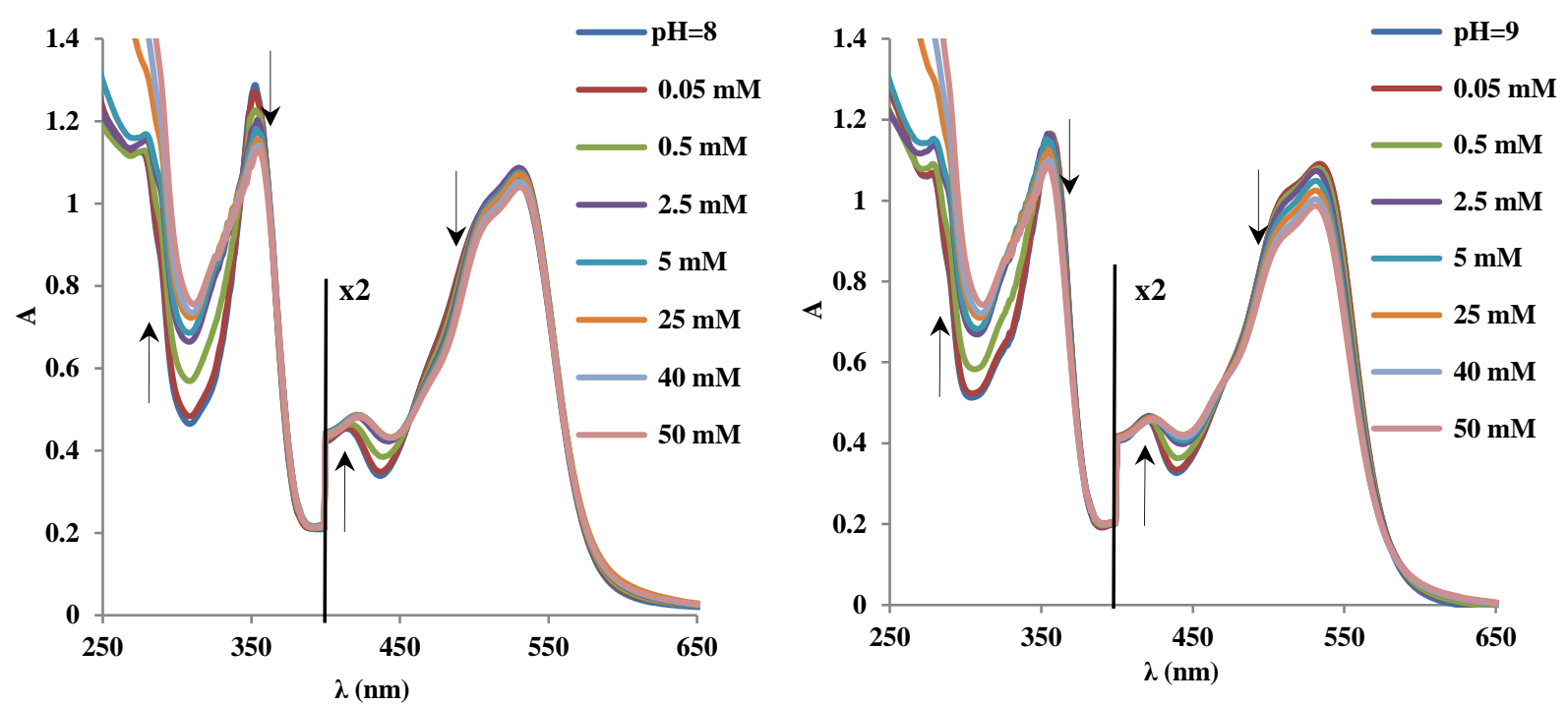

Figure S4. Titration of $\mathrm{Cbl}$ with hydrogen peroxide at $\mathrm{pH} 8$ and 9. Conditions: $0.05 \mathrm{mM} \mathrm{Cbl,}$ 0.05-50 $\mathrm{mM} \mathrm{H}_{2} \mathrm{O}_{2}, 22^{\circ} \mathrm{C}$. 
Table S1. Experimental wavelengths (nm) and extinction coefficients $\left(10^{3 *} \mathrm{M}^{-1 *} \mathrm{~cm}^{-1}\right.$, in parentheses) for the four main maxima in the UV-vis spectrum of Cbl variants examined in the present study.

\begin{tabular}{|c|c|c|c|c|}
\hline & I & II & III & IV \\
\hline aquaCbl & $351(26.5)$ & $410(4.2)$ & $498(8.8)$ & $526(9.5)$ \\
\hline peroxoCbl & $358(22.6)$ & $418(4.7)$ & $504(9.4)$ & $532(10.3)$ \\
\hline hydroxoCbl & $358(21.7)$ & $419(4.6)$ & $514(9.3)$ & $535(10.4)$ \\
\hline cyanoCbl & $361(27.5)$ & $409(3.5)$ & $516(7.6)$ & $550(8.5)$ \\
\hline
\end{tabular}
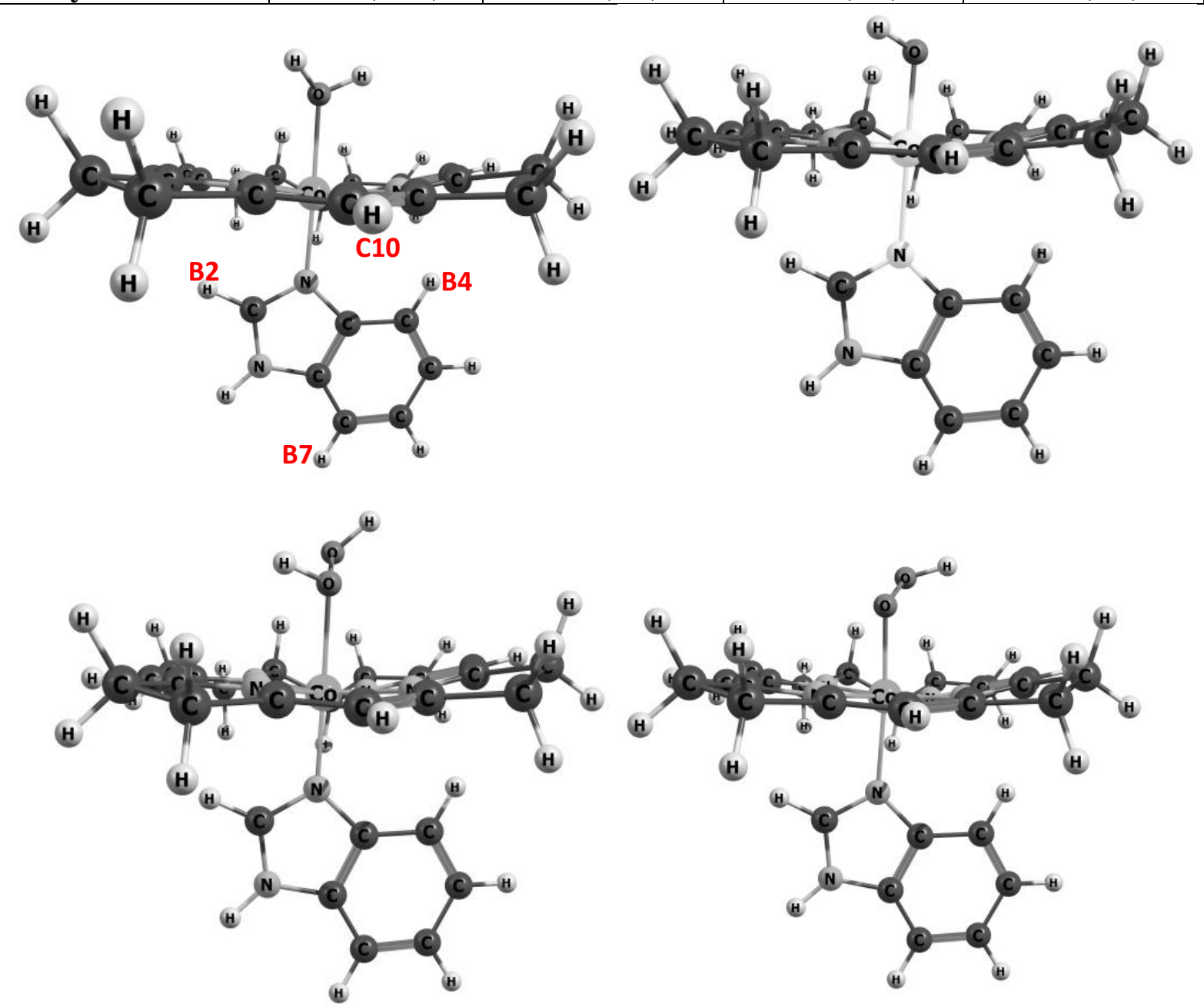

Figure S5. DFT-optimized geometries for Cbl complexes. Red labels indicate atoms discussed in the NMR section (see below). See also Table S2. 
Table S2. Key DFT-derived bond lengths ( $\AA$ ) in Cbl adducts. B3PW91-D3 data are reported, since this functional is the only one that reproduces the trends in maxima wavelength and intensity when comparing aqua vs. hydroxo cobalamin.

\begin{tabular}{|c|c|c|c|c|c|c|c|}
\hline Bond length & Cbl-OH & Cbl-HOH & Cbl-OOH & Cbl-OHOH & - OOH & HOOH & Cbl-CN $^{-1}$ \\
\hline Co-O/N & 1.86 & 2.05 & 1.88 & 2.08 & - & - & 1.88 \\
\hline Co-N(base) & 2.06 & 1.94 & 2.07 & 1.93 & - & - & 2.09 \\
\hline O-O/C-N & - & - & 1.42 & 1.43 & 1.52 & 1.45 & 1.16 \\
\hline
\end{tabular}

Table S3. TD-DFT-derived wavelengths (nm) and oscillator strengths (OS) for Cbl models with various axial ligands; the two most intense bands above $300 \mathrm{~nm}$ are reported.

\begin{tabular}{|c|c|c|c|c|c|c|c|c|c|}
\hline \multicolumn{2}{|c|}{ OOH- $^{-}$} & \multicolumn{2}{c|}{ H$_{2} \mathbf{O}_{2}$} & \multicolumn{2}{c|}{ OH$^{-}$} & \multicolumn{2}{c|}{ H$_{2}$ O } \\
\hline $\mathrm{nm}$ & OS & $\mathrm{nm}$ & OS & $\mathrm{nm}$ & OS & $\mathrm{nm}$ & OS & $\mathrm{nm}$ & OS \\
\hline 451 & 0.0919 & 427 & 0.0970 & 448 & 0.1110 & 434 & 0.1067 & 456 & 0.0970 \\
\hline 317 & 0.1137 & $302.18 /$ & $0.1347 /$ & 314 & 0.2204 & 310 & 0.3230 & 320 & 0.3486 \\
& & 310.62 & 0.1811 & & & & & & \\
\hline
\end{tabular}

Table S4. ${ }^{1} \mathrm{H}-\mathrm{NMR}$ peak assignments (in ppm) for $\mathrm{Cbl}$ complexes measured (expt.) and computed (DFT) in the present study. Labels (see also Figure S5) and assignments for cyanoCbl are from reference ${ }^{11}$.

\begin{tabular}{|c|c|c|c|c|c|c|c|c|c|c|}
\hline assignment & \multicolumn{3}{|c|}{$\delta\left(\mathrm{CN}^{-}\right)$} & \multicolumn{2}{c|}{$\delta\left(\mathrm{OH}_{2}\right)$} & \multicolumn{2}{c|}{$\delta\left(\mathrm{OH}^{-}\right)$} & \multicolumn{2}{c|}{$\delta\left(\mathrm{OH}^{-}\right)$} & $\delta\left(\mathrm{H}_{2} \mathrm{O}_{2}\right)$ \\
\hline & Ref. $^{11}$ & expt. & $D F T$ & expt. & DFT & expt. & DFT & expt. & $D F T$ & $D F T$ \\
\hline B4 & 7.28 & 7.12 & 7.48 & 7.01 & 7.08 & 7.01 & 7.59 & 6.95 & 7.35 & 7.03 \\
\hline B2 & 7.09 & 6.93 & 7.46 & 6.36 & 6.54 & 6.57 & 7.26 & 6.53 & 7.10 & 6.29 \\
\hline B7 & 6.51 & 6.35 & 7.69 & 6.31 & 7.96 & 6.34 & 7.72 & 6.25 & 7.67 & 7.92 \\
\hline C10 & 6.09 & 5.94 & 5.95 & $6.09(\mathrm{~d})$ & 6.85 & 5.92 & 6.29 & 5.89 & 6.28 & 6.90 \\
\hline
\end{tabular}




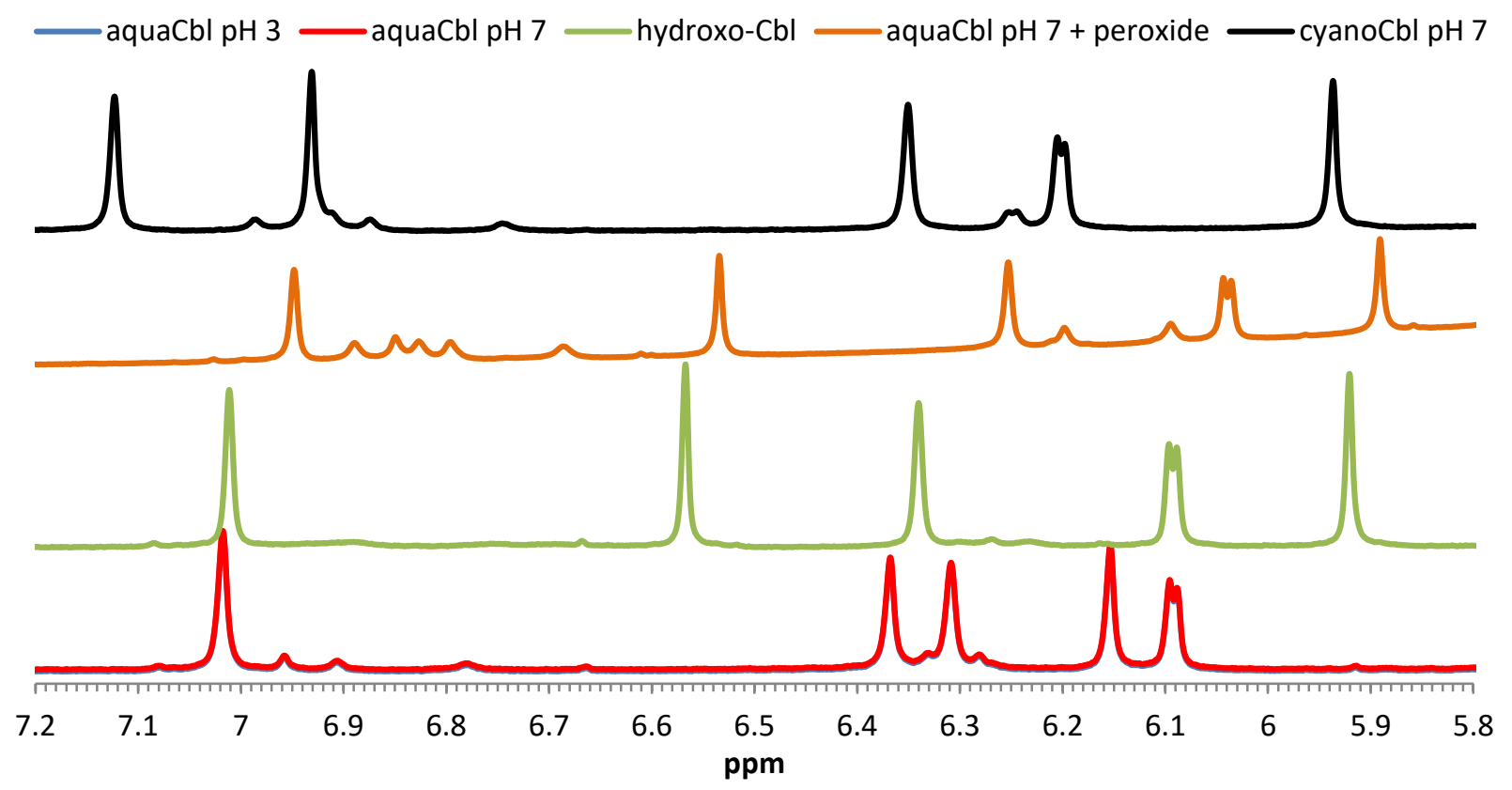

Figure S6. ${ }^{1} \mathrm{H}-\mathrm{NMR}$ spectra of $\mathrm{Cbl}$ in its aqua (pH 3 and 7), hydroxo (pH 10), cyano (pH 7) and peroxo (pH 7) states. Conditions: $5 \mathrm{mM} \mathrm{Cbl,} 50 \mathrm{mM} \mathrm{H}_{2} \mathrm{O}_{2}, 200 \mathrm{mM}$ phosphate (pH 3 and 7), 200 $\mathrm{mM}$ TRIS (pH 10), $22^{\circ} \mathrm{C}$.
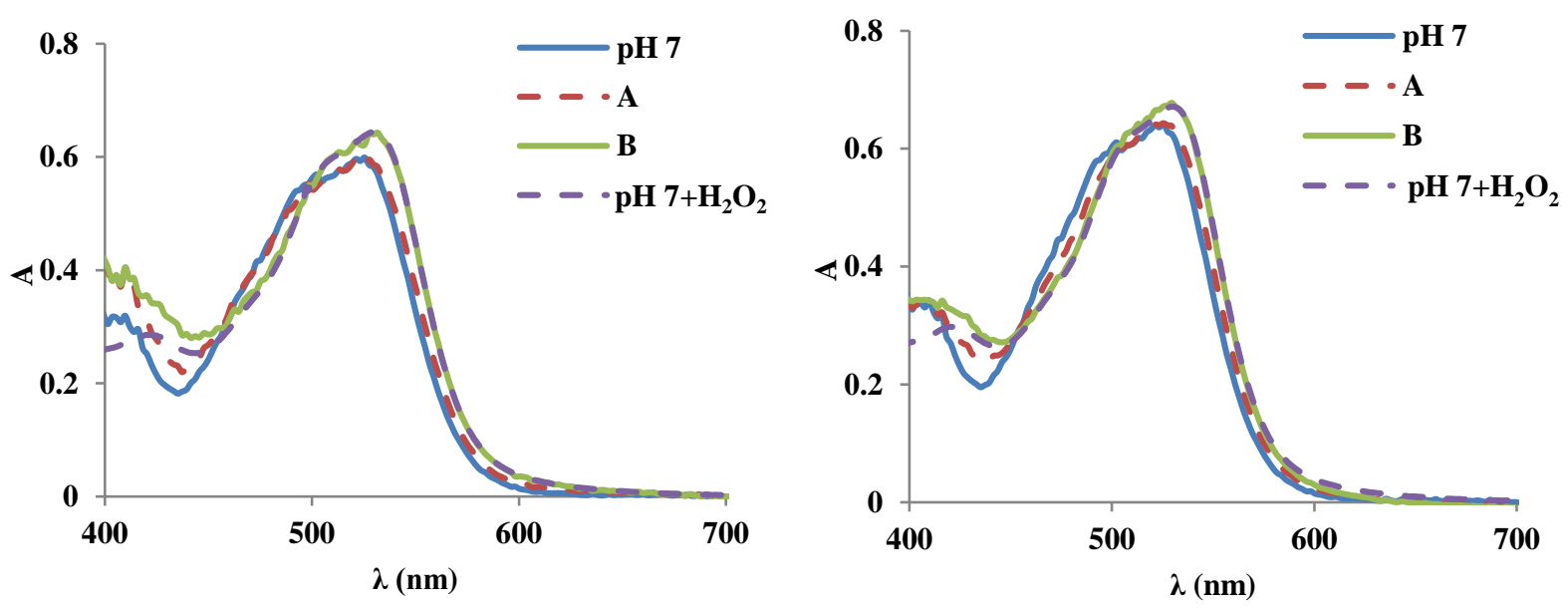

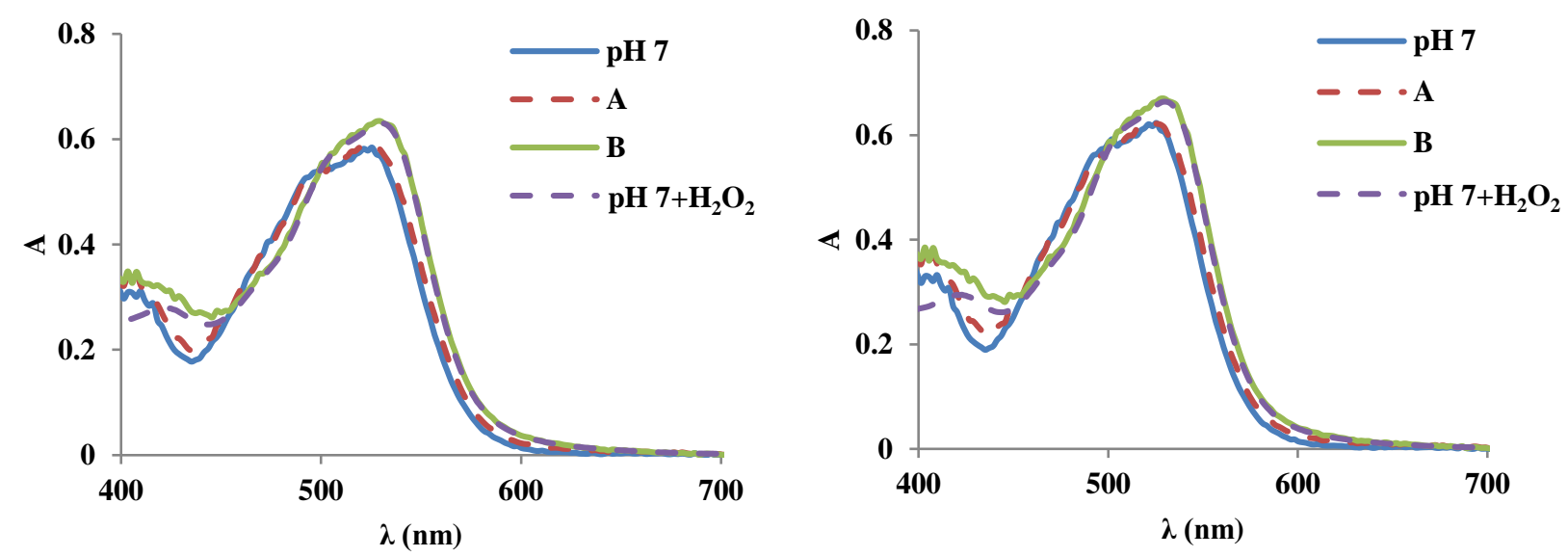

Figure S7. Calculated spectra of species involved (A and B) and time evolution of absorbance, for stopped-flow mixing of $\mathrm{Cbl}$ with peroxide. Shown for reference are static spectra of aquaCbl with and without peroxide, at the same $\mathrm{pH}$. Conditions: $50 \mathrm{mM}$ (upper left), $200 \mathrm{mM}$ (upper right), $75 \mathrm{mM}$ (lower left) and $150 \mathrm{mM}$ (lower right) $\mathrm{H}_{2} \mathrm{O}_{2}, 0.07 \mathrm{mM} \mathrm{Cbl,} \mathrm{pH} \mathrm{7,} 22^{\circ} \mathrm{C}$.

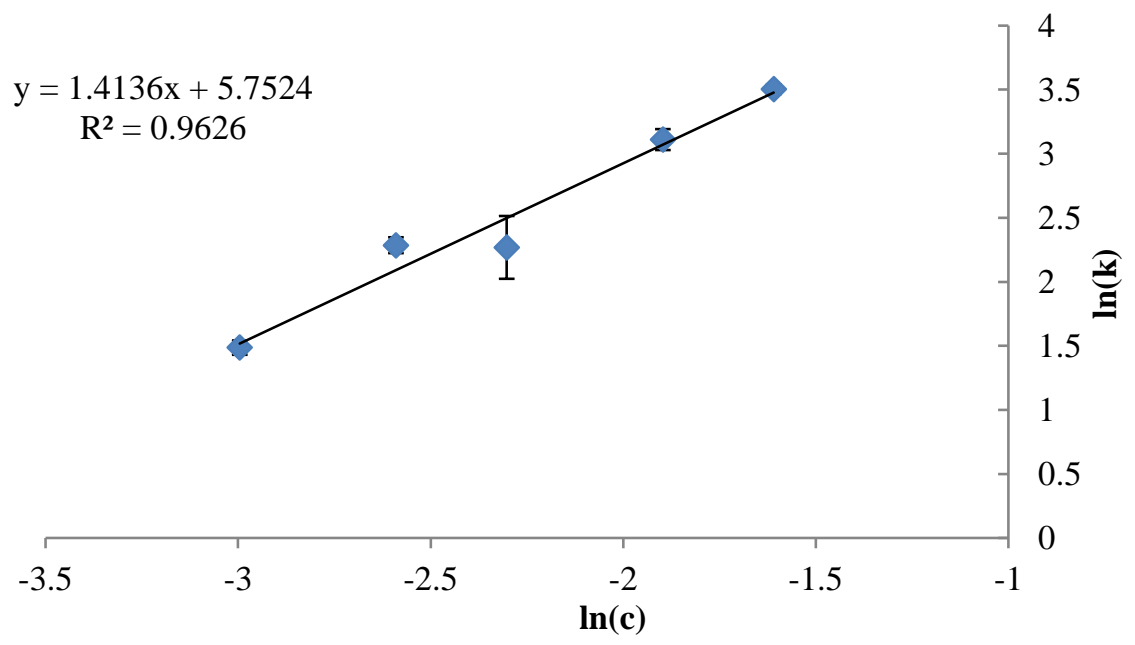

Figure S8. Logarithmic dependence of stopped-flow $\mathrm{k}_{\text {apparent }}$ on the peroxide concentration. Calculated rate constant: $4.5 \cdot 10^{6} \mathrm{M}^{-1} \cdot \mathrm{s}^{-1}$. 

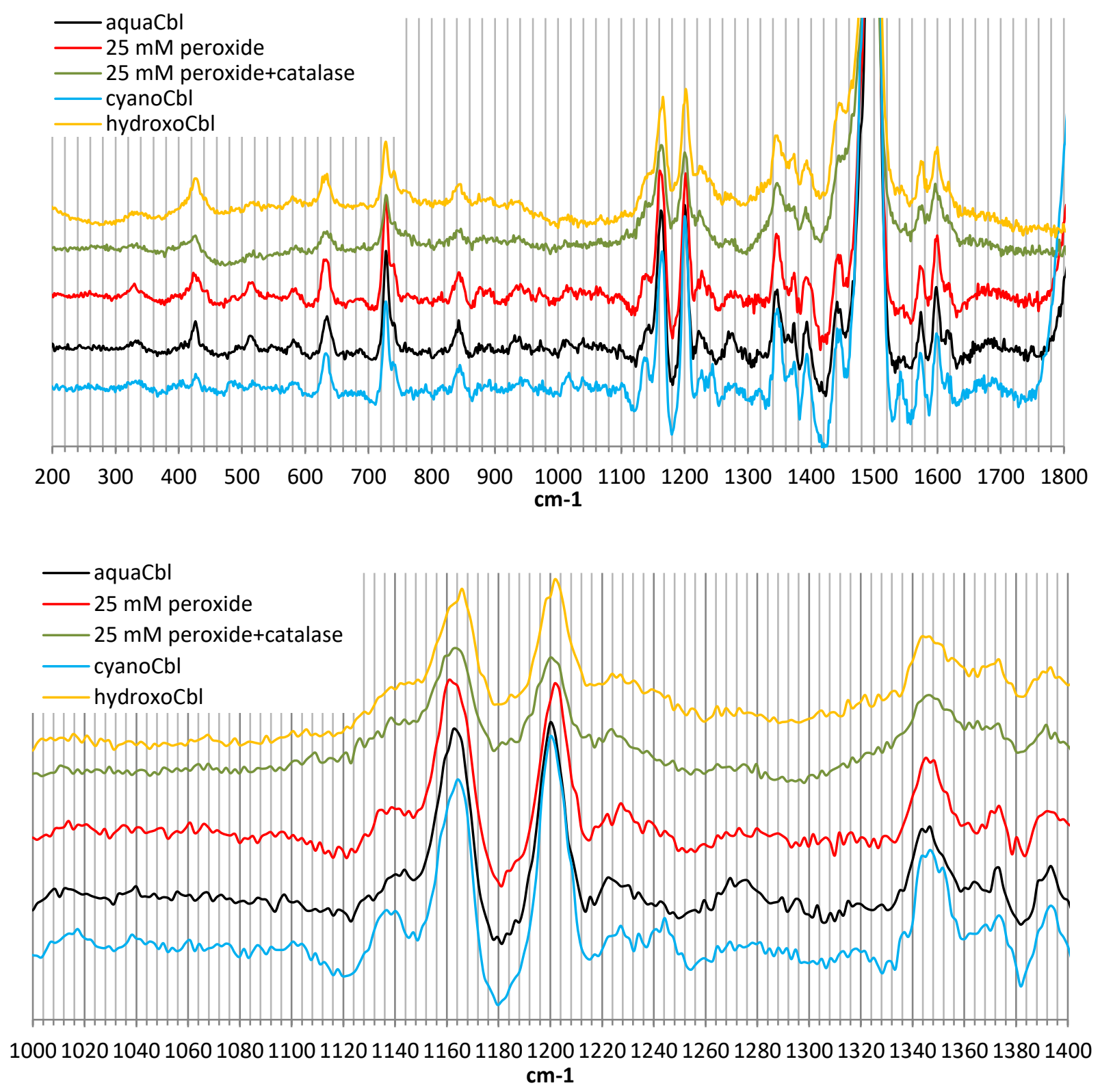

Figure S9. Resonance Raman spectra of $\mathrm{Cbl}$ in the presence or absence of hydrogen peroxide or cyanide. Conditions: $1 \mathrm{mM}$ aqua or cyano $\mathrm{Cbl}, 25 \mathrm{mM} \mathrm{H}_{2} \mathrm{O}_{2}, 50 \mathrm{mM}$ phosphate $\mathrm{pH} 7$ (for aqua, peroxo and cyano samples) or $50 \mathrm{mM}$ TRIS $\mathrm{pH} 10$ (for hydroxo-Cbl), $22^{\circ} \mathrm{C}$. 

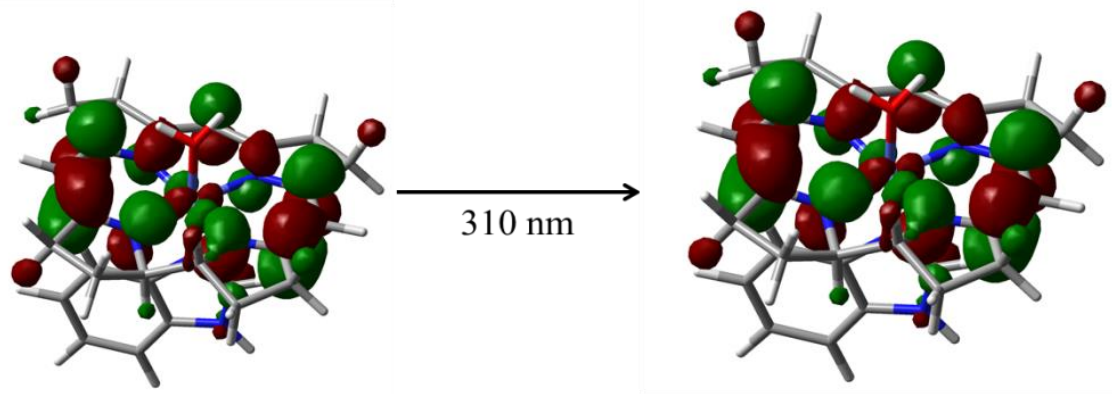

HOMO

$$
\mathrm{LUMO}+3
$$

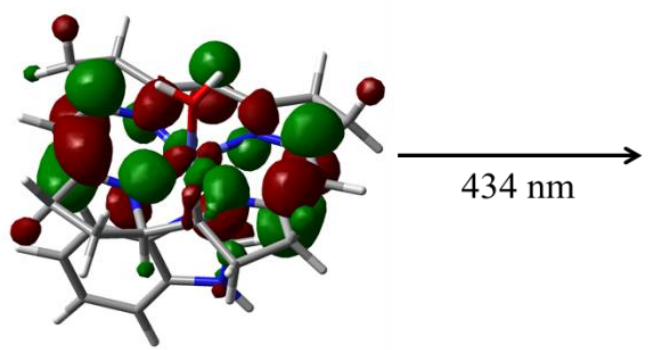

HOMO

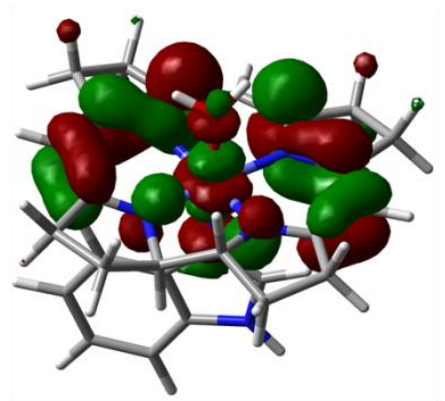

$\mathrm{LUMO}+1$

Figure S10. The main orbitals responsible for the main contributors to the two main bands in the TD-DFT spectra in aquaCbl cf. B3PW91 calculations.
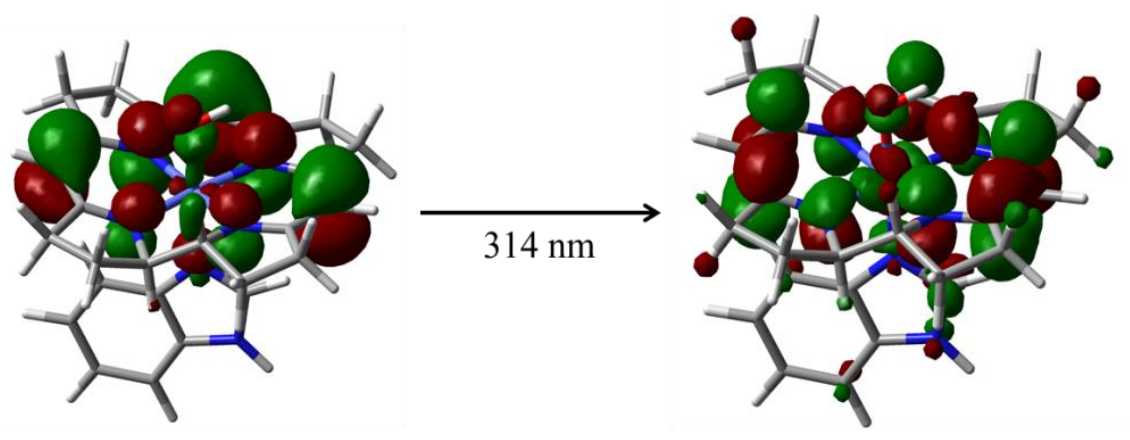

HOMO

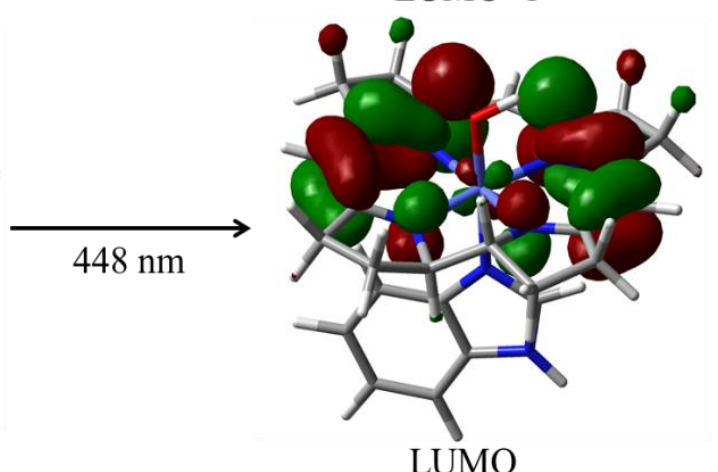

HOMO

LUMO

Figure S11. The main orbitals responsible for the main contributors to the two main bands in the TD-DFT spectra in hydroxoCbl cf. B3PW91 calculations. 


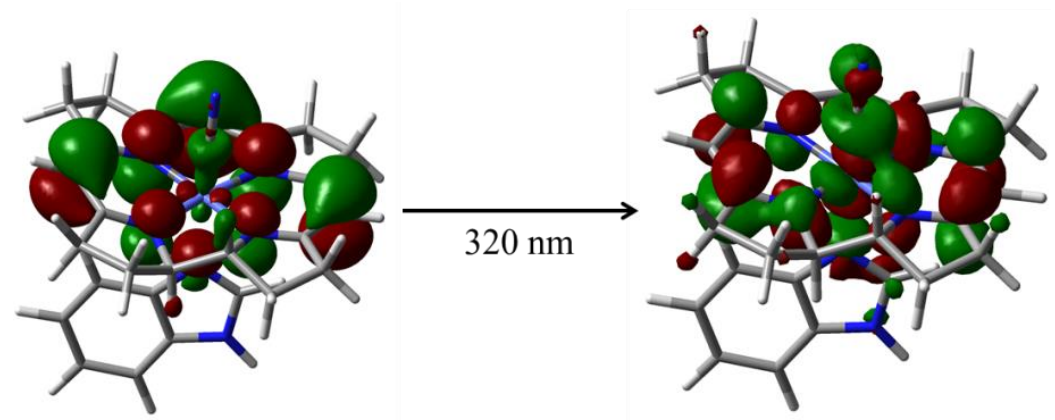

HOMO

LUMO+1

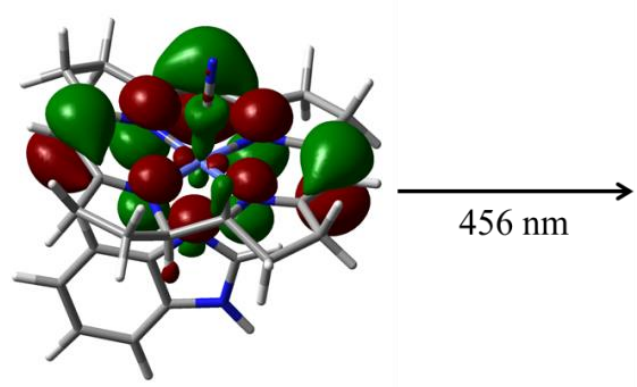

HOMO

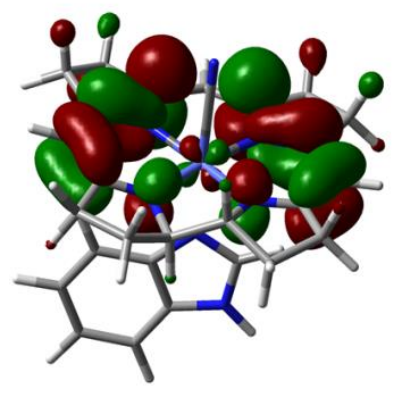

LUMO

Figure S12. The main orbitals responsible for the main contributors to the two main bands in the TD-DFT spectra in cyanoCbl cf. B3PW91 calculations.

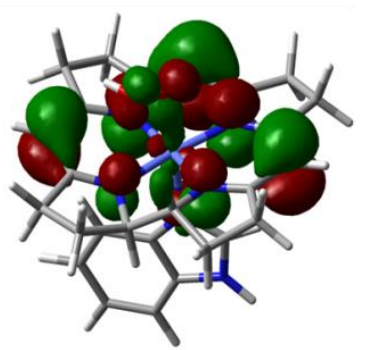

134 - HOMO

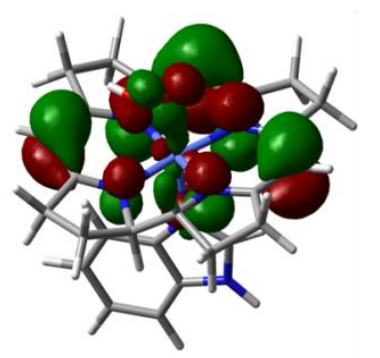

134 - HOMO

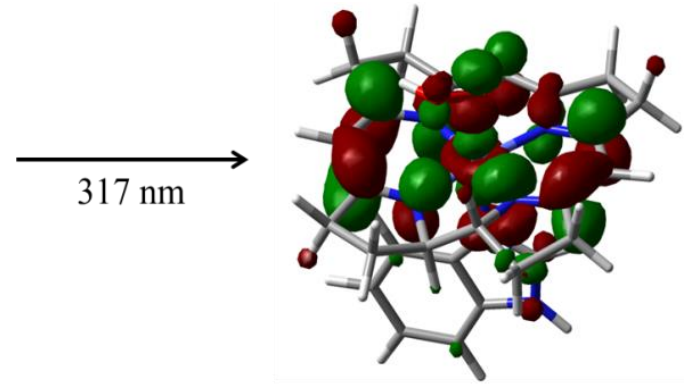

$137-\mathrm{LUMO}+2$

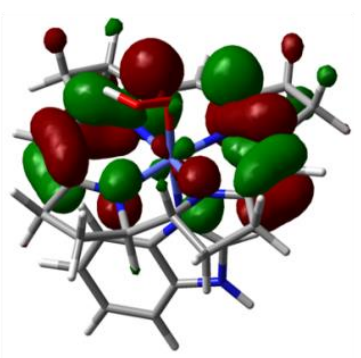

135 - LUMO

Figure S13. The main orbitals responsible for the main contributors to the two main bands in the TD-DFT spectra in hydroperoxoCbl cf. B3PW91 calculations. 

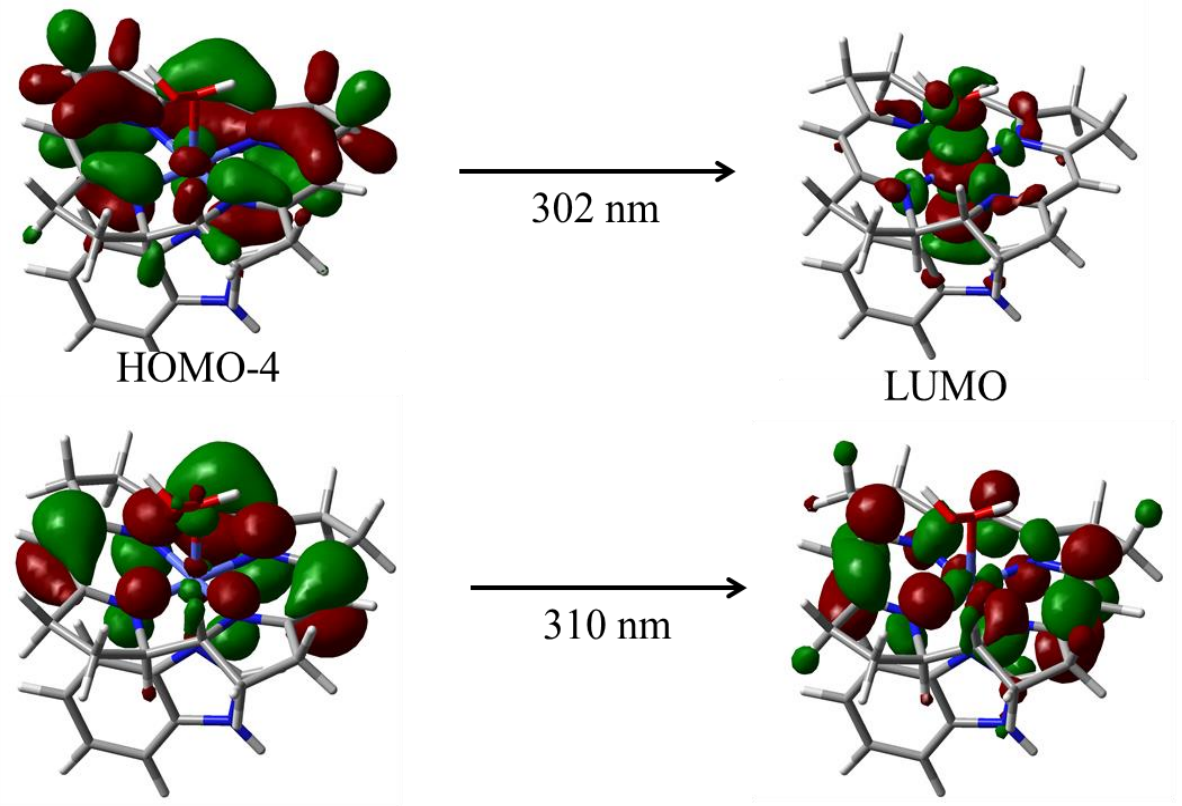

HOMO
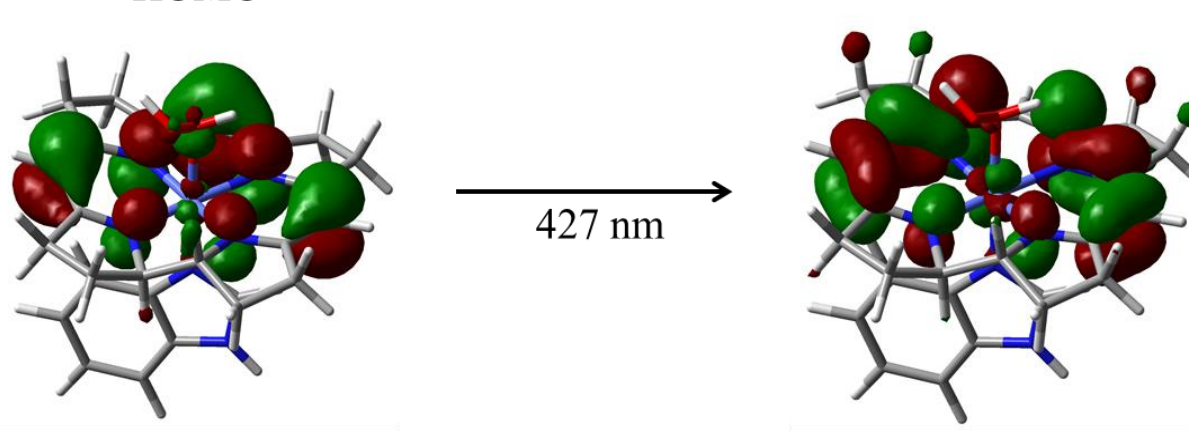

HOMO

Figure S14. The main orbitals responsible for the main contributors to the two main bands in the TD-DFT spectra in $\mathrm{H}_{2} \mathrm{O}_{2}$-Cbl cf. B3PW91 calculations. 

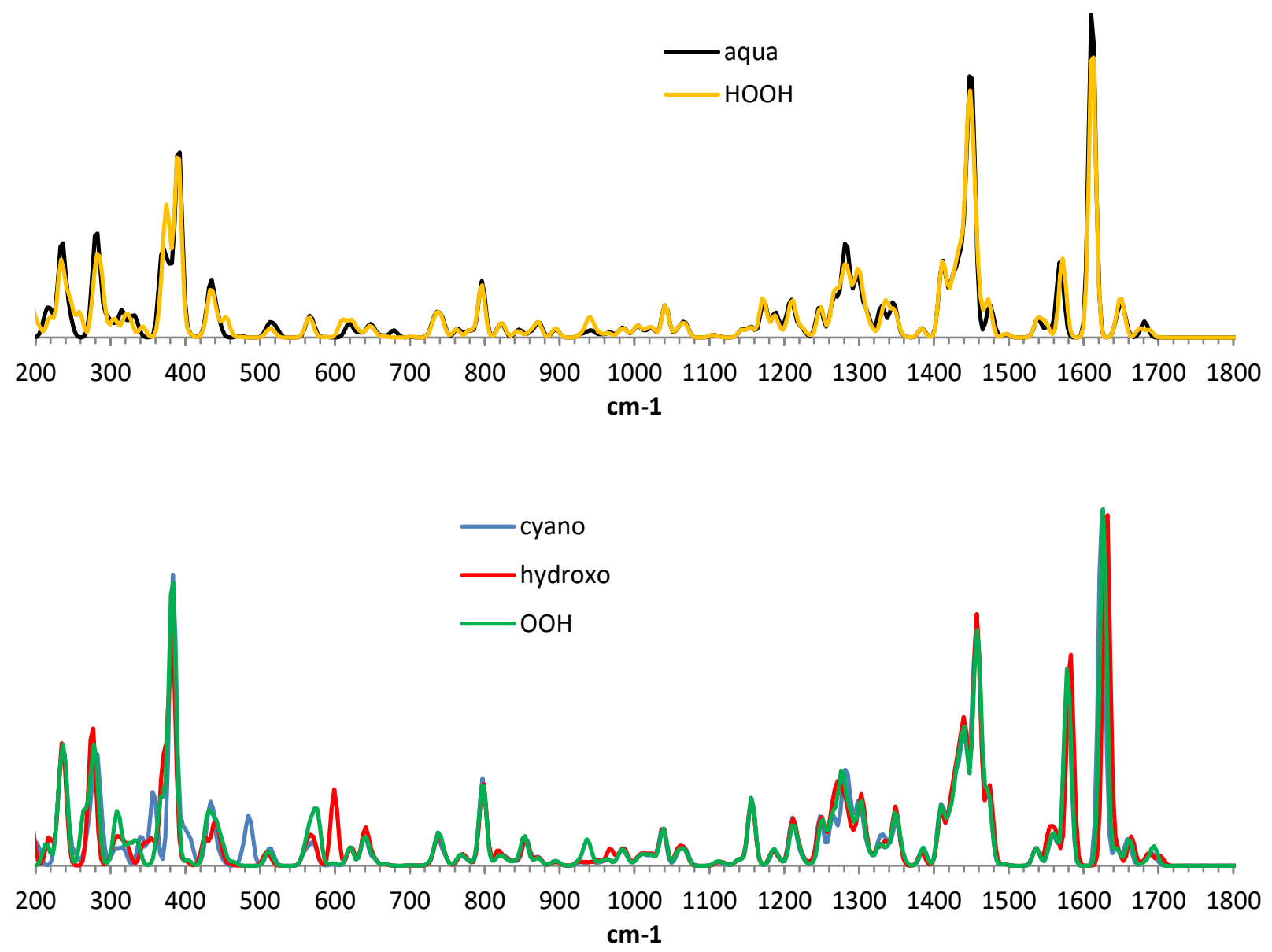

Figure S15. Raman spectra computed with DFT/B3LYP for Co(III)-cobalamin complexed with cyanide, water, hydroperoxide or hydrogen peroxide. 
Table S5. Main vibrations $\left(\mathrm{cm}^{-1}\right)$ observed experimentally for $\mathrm{Cbl}$ in the present study.

\begin{tabular}{|c|c|c|c|c|c|c|}
\hline Type & aquaCbl & $\mathrm{HO}-\mathrm{Cbl}$ & peroxo-Cbl & peroxoCbl+catalase & $\mathrm{CN}-\mathrm{Cbl}$ & Assignment $^{12-17}$ \\
\hline $\mathrm{W}$ & 1615 & 1615 & 1614 & 1615 & 1615 & \\
\hline $\mathrm{m}$ & 1598 & 1598 & 1588 & 1598 & 1598 & $\mathrm{C}=\mathrm{C}$ within corrin ring \\
\hline $\mathrm{m}$ & 1577 & 1577 & 1577 & 1577 & 1577 & \\
\hline $\mathrm{W}$ & 1544 & 1544 & 1547 & 1544 & 1544 & \\
\hline $\mathrm{s}$ & 1500 & 1500 & 1500 & 1500 & 1500 & $\mathrm{C}=\mathrm{C}$ within corrin ring \\
\hline $\mathrm{W}$ & 1446 & 1446 & 1446 & 1446 & 1446 & \\
\hline $\mathrm{w}$ & 1391 & 1391 & 1391 & 1391 & 1391 & \\
\hline $\mathrm{w}$ & 1373 & 1373 & 1373 & 1373 & 1373 & \\
\hline $\mathrm{m}$ & 1346 & 1346 & 1346 & 1346 & 1346 & corrin ring \\
\hline $\mathrm{vw}$ & 1269 & 1269 & 1269 & 1269 & 1277 & \\
\hline vw & & & & & 1240 & \\
\hline vw & & & & & 1227 & \\
\hline $\mathrm{vW}$ & 1222 & 1222 & 1222 & 1222 & & \\
\hline $\mathrm{s}$ & 1201 & 1201 & 1193 & 1201 & 1201 & \\
\hline $\mathrm{s}$ & 1164 & 1164 & 1171 & 1164 & 1164 & $\mathrm{PO}_{4}^{3-}$ \\
\hline $\mathrm{w}$ & 1145 & 1145 & 1140 & 1145 & 1145 & \\
\hline $\mathrm{vw}$ & 1015 & 1015 & 1015 & 1015 & 1015 & $\mathrm{PO}_{4}^{3-}$ \\
\hline $\mathrm{w}$ & 846 & 846 & 846 & 846 & 846 & 5,6-Dimethylbenzimidazole \\
\hline $\mathrm{W}$ & 740 & 740 & 740 & 740 & 740 & \\
\hline $\mathrm{m}$ & 727 & 727 & 727 & 727 & 727 & \\
\hline $\mathrm{m}$ & 630 & 630 & 630 & 630 & 630 & \\
\hline $\mathrm{vw}$ & 581 & 583 & 583 & 581 & 583 & $\mathrm{Co}-\mathrm{O}$ \\
\hline $\mathrm{w}$ & 514 & 516 & 516 & 514 & 518 & \\
\hline $\mathrm{VW}$ & & & & & 484 & $\mathrm{Co}-\mathrm{CN}$ \\
\hline $\mathrm{W}$ & 426 & 426 & 424 & 426 & 426 & corrin ring \\
\hline
\end{tabular}

Table S6. Main stretching vibrations $\left(\mathrm{cm}^{-1}\right)$ associated with the Co and axial ligands in Cbl Co$\mathrm{X}-\mathrm{Y}(\mathrm{X}-\mathrm{Y}=\mathrm{CN}, \mathrm{O}, \mathrm{OO})$ models (B3LYP).

\begin{tabular}{|c|c|c|c|c|}
\hline Bond/Model & $\mathrm{OOH}^{-}$ & $\mathrm{H}_{2} \mathrm{O}_{2}$ & $\mathrm{CN}^{-}$ & $\mathrm{H}_{2} \mathrm{O}$ \\
\hline Co-X & $563 / 572$ & $177 / 280 / 332$ & 438 & $200-440^{*}$ \\
\hline Co-N & $636 / 893 / 974$ & $560 / 993$ & $636 / 893 / 973$ & $200-$ \\
& & & & $440 * / 642 / 893 / 993 / 1216$ \\
\hline $\mathrm{X}-\mathrm{Y}$ & $936 / 942$ & $937 / 942$ & 2288 & - \\
\hline
\end{tabular}

*multiple vibrations throughout range 


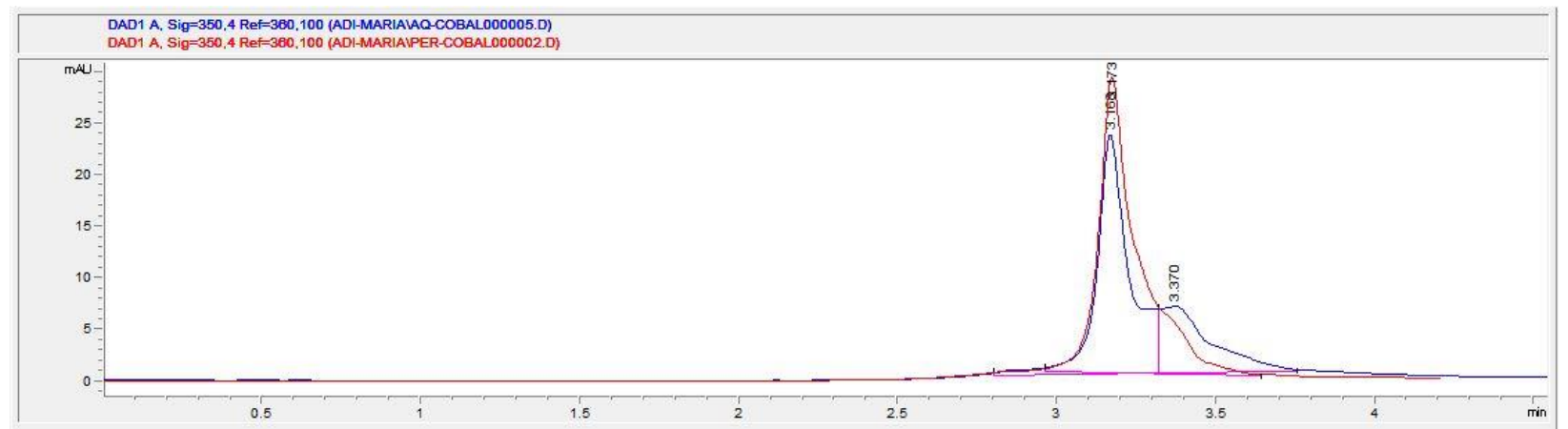

Figure S16. LC-UV-vis chromatograms of aquaCbl before (blue trace) and after (red trace) treatment with hydrogen peroxide, monitored at $350 \mathrm{~nm}$.

\section{References:}

(1) Frisch, M. J. et al. Gaussian 09, Revision E.01, Gaussian, Inc., Wallingford CT, 2013.

(2) Becke, A. D. Density-Functional Thermochemistry. III. The Role of Exact Exchange. $J$ Chem Phys 1993, 98 (7), 5648-5652. https://doi.org/10.1063/1.464913.

(3) Lee, C.; Yang, W.; Parr, R. G. Development of the Colle-Salvetti Correlation-Energy Formula into a Functional of the Electron Density. Phys Rev B 1988, 37 (2), 785-789. https://doi.org/10.1103/PhysRevB.37.785.

(4) Schäfer, A.; Horn, H.; Ahlrichs, R. Fully Optimized Contracted Gaussian Basis Sets for Atoms Li to Kr. J Chem Phys 1992, 97 (4), 2571-2577. https://doi.org/10.1063/1.463096.

(5) Brânzanic, A. M. V.; Ryde, U.; Silaghi-Dumitrescu, R. Importance of the Iron-Sulfur Component and of the Siroheme Modification in the Resting State of Sulfite Reductase. $J$ Inorg Biochem 2020, 203, 110928. https://doi.org/10.1016/j.jinorgbio.2019.110928.

(6) Ditchfield, R. Self-Consistent Perturbation Theory of Diamagnetism I. A Gauge-Invariant LCAO Method for N.M.R. Chemical Shifts. Mol Phys 1974, 27 (4), 789-807. https://doi.org/10.1080/00268977400100711.

(7) Barone, V.; Cossi, M. Conductor Solvent Model. J Phys Chem A 1998, 102 (97), 19952001.

(8) Perdew, J. P.; Wang, Y. Pair-Distribution Function and Its Coupling-Constant Average for the Spin-Polarized Electron Gas. Phys Rev B 1992, 46 (20), 12947- 12954.

(9) SPARTAN'06 for Windows, Wavefunction Inc., 18401 Von Karman Avenue, Suite 370 Irvine, CA 92612. 2006.

(10) Chemcraft - Graphical Software for Visualization of Quantum Chemistry Computations.

(11) Kurumaya, K.; Kajiwara, M. Proton Nuclear Magnetic Resonance (1H-NMR) Signal 
Assignment of Vitamin $\mathrm{B}_{12}$ Based on Normal Two-Dimensional NMR and Feeding Experiments. Chem Pharm Bull 1989, 31 (1), 9-12.

(12) Dong, S.; Padmakumar, R.; Banerjee, R.; Spiro, T. G. Co-C Force Constants from Resonance Raman Spectra of Alkylcobalamins: Insensitivity to Dimethylbenzylimidazole Coordination. Inorg Chim Acta 1998, 270 (1-2), 392-398. https://doi.org/10.1016/s00201693(97)05994-x.

(13) Salama, S.; Spiro, T. G. Visible and Near-ultraviolet Resonance Raman Spectra of Photolabile Vitamin B12 Derivatives with a Rapid-flow Technique. J Raman Spectrosc 1977, 6 (2), 57-60. https://doi.org/10.1002/jrs.1250060202.

(14) Galluzzi, F.; Garozzo, M.; Ricci, F. F. Resonance Raman Scattering and Vibronic Coupling in Aquo- and Cyano-cobalamin. J Raman Spectrosc 1974, 2 (4), 351-362. https://doi.org/10.1002/jrs.1250020405.

(15) Mayer, E.; Gardiner, D. J.; Hester, R. E. Resonance Raman Spectra of Vitamin B12 and Dicyanocobalamin. BBA - Gen Subj 1973, 297 (2), 568-570.

https://doi.org/10.1016/0304-4165(73)90107-4.

(16) Tsiminis, G.; Schartner, E. P.; Brooks, J. L.; Hutchinson, M. R. Measuring and Tracking Vitamin B 12 : A Review of Current Methods with a Focus on Optical Spectroscopy. Appl Spectrosc Rev 2017, 52 (5), 439-455. https://doi.org/10.1080/05704928.2016.1229325.

(17) Zhang, Z.; Wang, B.; Yin, Y.; Mo, Y. Surface-Enhanced Raman Spectroscopy of Vitamin $\mathrm{B}_{12}$ on Silver Particles in Colloid and in Atmosphere. J Mol Struct 2009, 927 (1-3), 8890. https://doi.org/10.1016/j.molstruc.2009.02.019. 